\title{
ESPÉCIES ARBÓREAS INVASORAS NO PAISAGISMO DOS PARQUES URBANOS DE CURITIBA, PR
}

\author{
Daniela Biondi ${ }^{1}$, Eduardo Muller ${ }^{2}$ \\ ${ }^{1}$ Eng $^{\mathrm{a}}$. Florestal, Dra ${ }^{\mathrm{a}}$., Depto. Ciências Florestais, UFPR, Curitiba, PR, Brasil - dbiondi@ufpr.br \\ ${ }^{2}$ Eng. Florestal, Curitiba, PR, Brasil - eduardommuller1@ gmail.com
}

Recebido para publicação: 11/09/2012 - Aceito para publicação: 23/02/2013

\begin{abstract}
Resumo
O objetivo deste trabalho foi caracterizar as espécies arbóreas introduzidas no paisagismo de cinco parques urbanos de Curitiba, principalmente no aspecto relativo às espécies exóticas invasoras. Sortearam-se aleatoriamente cinco parques: Passeio Público, Parque Bacacheri, Parque São Lourenço, Parque Barigui e Parque Municipal do Passaúna. As árvores foram identificadas quanto a taxonomia e origem. Foram analisados 5525 indivíduos arbóreos, sendo identificados 95,9\% até o nível de espécie. Da população analisada, foram identificadas 149 espécies e 48 famílias. Apenas 7 famílias representam $50 \%$ do total, com predominância de Fabaceae (20,8\%), sendo que o maior número de famílias verificou-se no Parque São Lourenço. Quanto à origem, 38,25\% são nativas de Curitiba, 24,83\% são espécies nativas do Brasil e 24,83\% são espécies exóticas. Encontraram-se 13 espécies exóticas invasoras: Citrus limon, Eriobotrya japonica, Eucalyptus grandis, Eucalyptus robusta, Eucalyptus viminalis, Eucalyptus sp., Hovenia dulcis, Ligustrum lucidum, Melia azedarach, Morus nigra, Pinus elliottii, Pinus sp. e Pittosporum undulatum. Psidium guajava foi a única espécie nativa do Brasil considerada invasora no Paraná. O Passeio Público foi o parque com maior número de espécies exóticas invasoras, enquanto o Parque Municipal do Passaúna apresentou maior número de espécies nativas de Curitiba.

Palavras-chave: Áreas verdes; espécies exóticas; espécies nativas.
\end{abstract}

\begin{abstract}
Invasive tree species in urban parks landscaping of Curitiba, $P R$. The aim of this study was to characterize the introduced tree species in landscaping of five urban parks of Curitiba, mainly concerning invasive species. Five parks were randomly selected: "Passeio Público", "Parque Bacacheri", "Parque São Lourenço", "Parque Bariguil" and "Parque Municipal do Passaúna". The trees were identified according to the taxonomy and origin. 5525 trees were analyzed, 95.9\% were identified at species level. From the analyzed population, 149 species were identified as well as 48 families. Only 7 families represent $50 \%$ of all families, with a predominance of Fabaceae (20.8\%), and the largest number of families was found in "Parque São Lourenço". In relation to the origin, $38.25 \%$ of trees are native of Curitiba, $24.83 \%$ are native of Brazil and 24.83\% are exotic species. 13 invasive alien species had been found: Citrus limon, Eriobotrya japonica, Eucalyptus grandis, Eucalyptus robusta, Eucalyptus viminalis, Eucalyptus sp. Hovenia dulcis, Ligustrum lucidum, Melia azedarach, Morus nigra, Pinus elliottii, Pinus sp and Pittosporum undulatum. Psidium guajava was the only Brazil native species considered invasive in Paraná. The "Passeio Público" is the park with the highest number of invasive alien species, and the "Parque Municipal Passaúna" had the greatest number of native species of Curitiba.

Keywords: Green areas; alien species; indigenous species.
\end{abstract}

\section{INTRODUÇÃO}

A trajetória do planejamento urbano e paisagístico segue diferentes tendências e modelos ou paradigmas, fundamentados em categorias e conceitos que caracterizam o pensamento de cada época (ÁLVARES; DIAS, 2008). O desenvolvimento das linhas projetuais dos parques públicos urbanos brasileiros sofreu grandes transformações ao longo de seus quase duzentos anos de existência - ora surgem com figurações naturalistas, ora recriam cenários fantásticos, ora simplesmente conservam e possibilitam ao público o acesso a bosques (MACEDO; SAKATA, 2010). 
Independentemente das linhas projetuais e da época de criação dos parques urbanos, atualmente a vegetação tem sido alvo de preocupação dos paisagistas, dos pesquisadores e da municipalidade. No momento, o questionamento da importância da vegetação de qualidade nas áreas verdes está fortemente relacionado à conservação dos ecossistemas locais e/ou nacionais. Tanto a vegetação introduzida como a remanescente nas cidades depende e tem grande influência da administração municipal, no que se refere às áreas públicas (praças, parques, jardins de instituições públicas e arborização de ruas), e da população local nas áreas particulares. Além desses fatores políticos e culturais, o fator econômico também pode influenciar na quantidade e na qualidade da vegetação urbana (BIONDI; PEDROSA-MACEDO, 2008).

Segundo Ziller et al. (2004), espécies exóticas invasoras são aquelas que ocorrem numa área fora de seu limite natural historicamente conhecido, como resultado de dispersão acidental ou intencional por atividades humanas. As espécies exóticas invasoras são reconhecidas como a segunda causa mundial para a perda de diversidade biológica, perdendo apenas para a destruição de hábitats e para a exploração humana direta. Essas espécies, quando introduzidas em outros ambientes, livres de inimigos naturais, se adaptam e passam a reproduzir-se a ponto de ocupar o espaço de espécies nativas e produzir alterações nos processos ecológicos naturais, tendendo a se tornar dominantes após um período de tempo mais ou menos longo requerido para sua adaptação.

O primeiro passo para a evolução e a popularização do controle da vegetação exótica invasora nos parques e outras áreas urbanas é a criação de um suporte legal (por meio de pesquisas científicas, laudos e pareceres técnicos que deem origem às leis) no âmbito municipal e/ou estadual.

Sakata (2011) reconhece que a cidade de Curitiba-PR, durante os anos 1990, divulgou a imagem de cidade ecológica, que era sustentada pelos parques e ciclovias, por legislação ambiental moderna e por programas de coleta de lixo. Considerando as palavras da autora e enfatizando o espírito inovador, não só da cidade como também do estado do Paraná, pode-se dizer que eles foram também precursores na normatização da terminologia relativa à vegetação exótica invasora no Brasil.

Sendo assim, a Portaria do Instituto Ambiental do Paraná (IAP) no 095/2007 reconhece a lista oficial de espécies exóticas invasoras (flora e fauna) para o estado do Paraná, estabelecendo normas de controle e outras providências. Nela foram definidas espécies exóticas - espécies, subespécies ou táxons inferiores introduzidos fora da sua área natural de distribuição presente ou passada, incluindo qualquer parte, gametas, sementes, ovos ou propágulos dessas espécies que possam sobreviver e posteriormente reproduzir-se - e espécies exóticas invasoras - espécies exóticas cuja introdução ou dispersão ameaça ecossistemas (PARANÁ, 2007).

Para as espécies arbóreas, no contexto municipal, o Decreto n 473/2008 define as espécies florestais consideradas como exóticas invasoras para o Município de Curitiba e dá outras providências. Para efeito desse decreto, conceituou-se "espécies florestais exóticas invasoras" como aquelas introduzidas fora de sua área natural de distribuição, presente ou passada, cuja dispersão ameaça ecossistemas, hábitats, ou espécies que causam impactos ambientais, econômicos, sociais ou culturais (CURITIBA, 2008).

Reconhecendo a importância desse tema e considerando que as espécies arbóreas exóticas invasoras utilizadas no paisagismo dos parques urbanos ameaçam a conservação das áreas remanescentes de floresta, o objetivo deste trabalho foi caracterizar as espécies arbóreas do tratamento paisagístico de cinco parques urbanos de Curitiba, principalmente no aspecto relativo às espécies exóticas invasoras.

\section{MATERIAL E MÉTODOS}

\section{Localização e caracterização da área de estudo}

O município de Curitiba localiza-se no Primeiro Planalto Paranaense e no Bioma da Mata Attântica. Possui uma área de 435,27 km2 e está situado a $25^{\circ} 25^{\prime} 40^{\prime \prime}$ de latitude sul e $49^{\circ} 16^{\prime 2} 23^{\prime \prime}$ de longitude oeste. O clima é classificado como subtropical úmido, com temperaturas médias de $19,7^{\circ} \mathrm{C}$ no verão e $13,4^{\circ} \mathrm{C}$ no inverno. Devido à sua posição e às suas características topográficas, situando-se ao sul do Trópico de Capricórnio e num planalto com altitude média de 934,60 m acima do mar, o verão é ameno e o inverno moderado, com alguns dias mais rigorosos. A média anual de precipitação é de $1.419,91 \mathrm{~mm}$, com período de estiagem entre o outono e o inverno. A direção dos ventos predominantes é NE-SO (INSTITUTO DE PESQUISA E PLANEJAMENTO URBANO DE CURITIBA (IPPUC), 2011a).

A cidade de Curitiba é conhecida nacionalmente pela quantidade e qualidade de suas áreas verdes urbanas. Segundo IPPUC (2011b), Curitiba está entre as grandes cidades do mundo premiadas 
pela edição 2010 da competição World Design Capital - Capital Mundial do Design (WDC) -, realizada em Seul, na Coreia do Sul. Curitiba foi escolhida na categoria Política de Desenvolvimento Urbano e é citada como uma cidade que tem um plano diretor para orientar o crescimento, contemplando transportes, circulação, uso da terra e meio ambiente de forma integrada. Inclui ainda medidas de preservação de áreas verdes e das heranças históricas e culturais.

Segundo levantamento da Secretaria Municipal de Meio Ambiente, em 2000 o município contava com 30 unidades de parques e bosques, 11 núcleos ambientais, 5 jardins ambientais, 54 largos, 15 eixos de animação, 330 jardinetes (Secretaria Municipal de Meio Ambiente de Curitiba - SMMAC, 2006) e 453 praças (IPPUC, 2011b).

\section{Descrição das áreas verdes}

Das 30 áreas verdes de Curitiba da tipologia parques e bosques, foram sorteadas aleatoriamente cinco parques, representando 16,67\% do total: Passeio Público, Parque General Iberê de Mattos (Bacacheri), Parque São Lourenço, Parque Barigui e Parque Municipal do Passaúna (Figura 1).
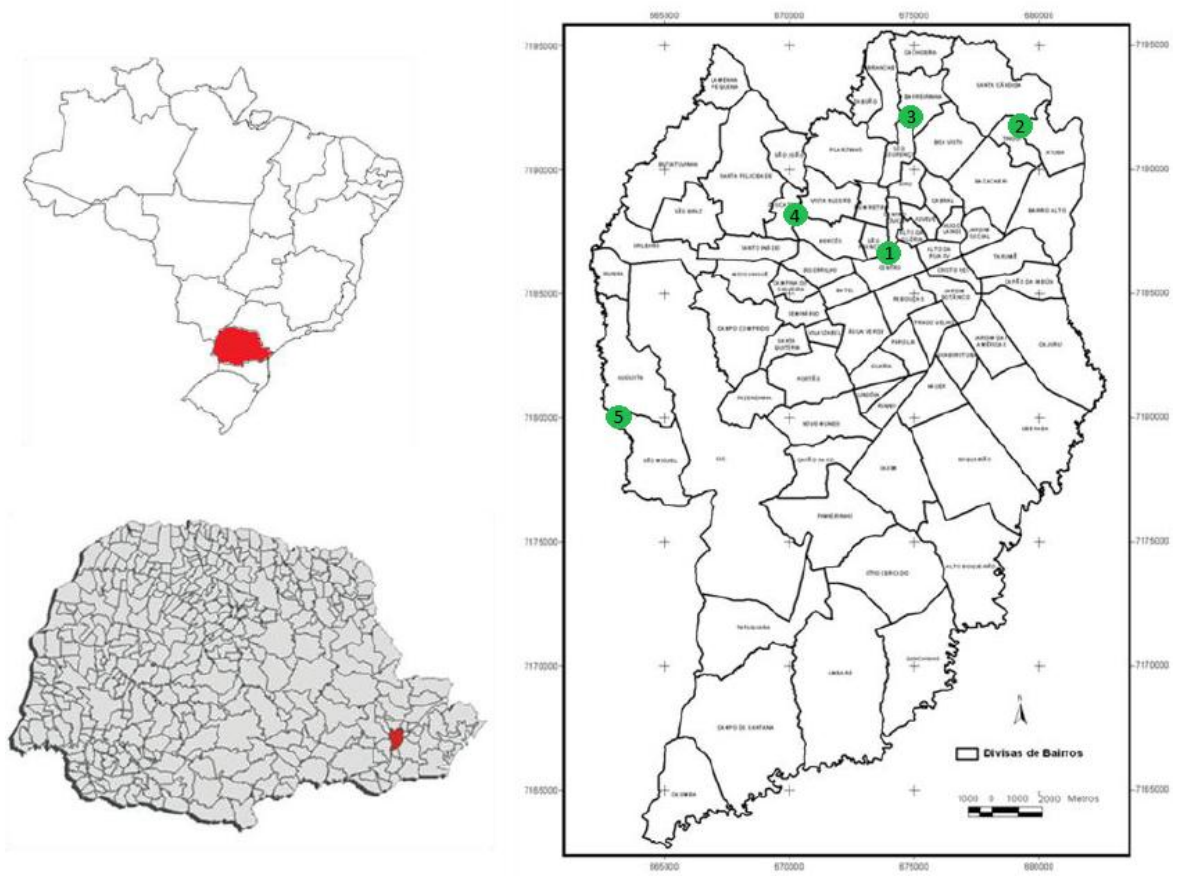

Figura 1. Localização dos parques analisados.

Figure 1. Location of analyzed parks.

Nota: 1: Passeio Público; 2: Parque Municipal do Bacacheri; 3: Parque São Lourenço; 4: Parque Municipal Barigui; 5: Parque Municipal do Passaúna.

O Passeio Público foi o primeiro parque de Curitiba. Inaugurado em 1886, apresentava cerca de $70 \mathrm{mil} \mathrm{m} \mathrm{m}^{2}$ de vegetação nativa nas margens do rio Belém. Ainda naquele século foi, por algum tempo, utilizado como Jardim Botânico de Curitiba e depois como o primeiro zoológico, sendo que até hoje possui alguns animais em cativeiro, além de um aquário. É considerado um santuário ecológico em pleno centro da cidade (PARQUES, 2012). Atividades que podem ser desenvolvidas: contemplação, recreação infantil, esportes e eventos culturais (MACEDO; SAKATA, 2010).

O Parque General Iberê de Mattos, mais conhecido por Parque Bacacheri, foi inaugurado em 1988, com uma área de $152 \mathrm{mil} \mathrm{m}^{2}$, e constitui uma boa opção de lazer para os moradores do bairro do Bacacheri. Essa região foi colonizada principalmente por imigrantes franceses e originários da Argélia, que chegaram em 1869. Possui canchas de futebol e de vôlei de areia, churrasqueiras, playground, lago artificial (PARQUES, 2012) e bosque de vegetação nativa. Atividades que podem ser desenvolvidas: conservação de recursos naturais, contemplação, esportes e recreação infantil (MACEDO; SAKATA, 2010). 
O Parque São Lourenço foi inaugurado em 1972 e se deu após uma enchente do rio Belém, em 1970, a qual provocou o rompimento da represa de São Lourenço, paralisando o curtume e a fábrica de cola que funcionavam no local. Possui área total igual a $204 \mathrm{mil} \mathrm{m}^{2}$, onde existem os seguintes equipamentos: Centro de Criatividade, pista para carrinhos de rolimã, churrasqueiras, cancha de vôlei, ciclovia, parque infantil (PARQUES, 2012) e bosques nativos com araucárias. Atividades que podem ser desenvolvidas: contemplação, esportes e recreação infantil, esportes e conservação de recursos naturais (MACEDO; SAKATA, 2010).

O Parque Municipal Barigui é um dos maiores e o mais frequentado de Curitiba. Possui uma área de 1,4 milhão $\mathrm{m}^{2}$, que fazia parte da sesmaria do capitão-povoador Mateus Leme. Foi transformado em parque em 1972, segundo o projeto do arquiteto Lubomir Ficinski. Possui equipamentos de ginástica, sede campestre, churrasqueiras, grande lago, restaurante, canchas poliesportivas, quiosques, Museu do Automóvel, Estação Maria Fumaça, parque de exposições, parque de diversão, heliporto, pista de bicicross e aeromodelismo. Também abriga a sede da Secretaria Municipal do Meio Ambiente (PARQUES, 2012).

O Parque Municipal do Passaúna é um dos mais belos parques de Curitiba. Foi inaugurado em 1991 e possui uma área de 6,5 milhões $\mathrm{m}^{2}$. Aproximadamente a metade dessa área foi recoberta pelo lago da represa da Estação de Abastecimento de Água do Passaúna, que abastece parte da cidade de Curitiba. Por isso, é considerada, por lei estadual e municipal, uma Área de Proteção Ambiental (APA). Possui uma trilha ecológica de 3,5 km beirando o lago, Estação Biológica, ancoradouro de barcos, parque infantil, pontes de madeira, churrasqueiras e um mirante de $60 \mathrm{~m}$ de altura (PARQUES, 2012).

\section{Procedimentos metodológicos}

A coleta foi realizada no período de agosto de 2009 a junho de 2010. Em cada área verde foi utilizada uma planilha para a coleta de campo com os seguintes dados: código da espécie; número de referência da espécie para identificação (exsicata); estágio de desenvolvimento (adulta ou jovem) e o número de indivíduos de cada espécie arbórea.

Todas as áreas verdes analisadas nesta pesquisa possuem um ou mais fragmentos de vegetação remanescente de Floresta Ombrófila Mista, além das árvores introduzidas no tratamento paisagístico. Somente as árvores introduzidas no tratamento paisagístico foram contempladas no levantamento florístico, sendo adotados os seguintes critérios de inclusão: (a) árvore isolada ou em agrupamentos fora das áreas do remanescente florestal, fazendo parte de uma composição com outras plantas ou complementando áreas específicas do parque, tais como estacionamento, playground, áreas com churrasqueiras, bordas de caminhos e outros; (b) mudas arbóreas com tronco sem ramificação na base (padrão para arborização de ruas de mudas produzidas no Horto Municipal da Barreirinha, Curitiba); (c) mudas arbóreas com presença de tutor (material utilizado pela prefeitura para apoiar ou sustentar a muda ereta), sendo que, em caso de dúvida, buscaram-se informações sobre o seu plantio com os funcionários do local.

Foi coletado, quando existente, material vegetal fértil (com flor e/ou fruto), para elaboração de exsicata e posterior identificação de espécies que não foram identificadas durante as coletas de campo. As exsicatas foram identificadas no Herbário do Curso de Engenharia Florestal da UFPR. Os nomes científicos e a autoria dos epítetos específicos foram conferidos pelo banco eletrônico do Jardim Botânico de Missouri (MISSOURI BOTANICAL GARDEN, 2012) e pela lista de espécies da flora do Brasil (MUSEU BOTÂNICO DO RIO DE JANEIRO, 2012).

Todas as árvores identificadas até o nível de espécie foram classificadas quanto à sua origem: nativa do Brasil ou exótica. As espécies nativas foram divididas em nativas do Brasil e nativas de Curitiba. As espécies exóticas foram divididas em exóticas e exóticas invasoras. Para fundamentação prática e legal, só foram consideradas espécies exóticas invasoras aquelas citadas na Portaria IAP n 095/2007 (PARANÁ, 2007) e no Decreto nº 473/2008, da Prefeitura Municipal de Curitiba (CURITIBA, 2008).

\section{RESULTADOS E DISCUSSÃO}

Nas cinco áreas verdes avaliadas, foram encontrados 5.525 indivíduos arbóreos, sendo identificados 95,9\% até o nível de espécie. Da população analisada, foram identificadas 149 espécies, distribuídas em 48 famílias (Tabela 1). As famílias com maior número de espécies foram: Fabaceae $(20,8 \%)$, Myrtaceae (8,7\%), Bignoniaceae (4,7\%), Arecaceae (4,7\%), Lauraceae $(4,0 \%)$, Moraceae $(4,0 \%)$ e Sapindaceae $(3,3 \%)$. Essas 7 famílias representam 50,2\% das espécies identificadas. 
Metade das espécies identificadas (75 espécies) ocorre em apenas um parque e 12\% das espécies (18 espécies) ocorrem simultaneamente em todos eles. O maior número de espécies foi encontrado no Passeio Público (81 espécies), seguido pelos parques São Lourenço (69 espécies) e Passaúna (57 espécies). O maior número de famílias foi encontrado no Parque São Lourenço (37 famílias), seguido do Passeio Público (32 famílias) e do Parque Municipal do Passaúna (30 famílias).

Tabela 1. Identificação das espécies arbóreas nos parques de Curitiba, PR.

Table 1. Tree species identification in parks of Curitiba, PR.

\begin{tabular}{|c|c|c|c|c|c|c|c|}
\hline \multirow{2}{*}{ Família / Nome científico } & \multirow{2}{*}{ Nome popular } & \multicolumn{5}{|c|}{ Parques } & \multirow[b]{2}{*}{5} \\
\hline & & $\overline{\mathbf{O}}$ & 1 & 2 & 3 & 4 & \\
\hline \multicolumn{8}{|l|}{ ANACARDIACEAE } \\
\hline Lithraea molleoides (Vell.) Engl. & Bugreiro & $\mathrm{N}_{\mathrm{c}}$ & & & $\mathrm{x}$ & & $\mathrm{x}$ \\
\hline Schinus sp. & Aroeira & & & & & & $\mathrm{x}$ \\
\hline Schinus molle L. & Aroeira-salsa & $\mathrm{N}_{\mathrm{c}}$ & $\mathrm{x}$ & & $\mathrm{x}$ & $\mathrm{x}$ & \\
\hline $\begin{array}{l}\text { Schinus terebinthifolius Raddi. } \\
\text { ANNONACEAE }\end{array}$ & Aroeira-vermelha & $\mathrm{N}_{\mathrm{c}}$ & $\mathrm{x}$ & $\mathrm{x}$ & $\mathrm{x}$ & $\mathrm{x}$ & $\mathrm{x}$ \\
\hline Annona sylvatica A. St.-Hil. & Araticum & $\mathrm{N}_{\mathrm{c}}$ & $\mathrm{x}$ & $\mathrm{x}$ & & $\mathrm{x}$ & $\mathrm{x}$ \\
\hline Annona sp. (1) & Araticum & & & & $\mathrm{x}$ & & \\
\hline Annona sp. (2) & Araticum & & & & $\mathrm{x}$ & & \\
\hline \multicolumn{8}{|l|}{ AQUIFOLIACEAE } \\
\hline Ilex dumosa Reissek & Congonha & $\mathrm{N}_{\mathrm{c}}$ & & & & & $\mathrm{x}$ \\
\hline Ilex paraguariensis A. St.-Hil. & Erva-mate & $\mathrm{N}_{\mathrm{c}}$ & $\mathrm{x}$ & & $\mathrm{x}$ & & $\mathrm{x}$ \\
\hline $\begin{array}{l}\text { Ilex theizans Mart. ex Reissek } \\
\text { ARAUCARIACEAE }\end{array}$ & Caúna & $\mathrm{N}_{\mathrm{c}}$ & & $\mathrm{x}$ & & & \\
\hline Araucaria angustifolia (Bert.) O.Ktze. & Pinheiro-do-paraná & $\mathrm{N}_{\mathrm{c}}$ & $\mathrm{x}$ & $\mathrm{x}$ & $\mathrm{x}$ & $\mathrm{x}$ & $\mathrm{x}$ \\
\hline $\begin{array}{l}\text { Araucaria columnaris Hook. } \\
\text { ARECACEAE }\end{array}$ & Araucaria-excelsa & $\mathrm{E}$ & $\mathrm{x}$ & & & & \\
\hline $\begin{array}{l}\text { Archontophoenix alexandrae (F. Muell.) H. Wendl. \& } \\
\text { Drude }\end{array}$ & Palmeira-real & $\mathrm{E}$ & $\mathrm{x}$ & & & & \\
\hline Butia capitata (Mart.) Becc. & Butiá (1) & $\mathrm{N}$ & $\mathrm{x}$ & & & & \\
\hline Butia eriospatha (Mart. ex Drude) Becc. & Butiá (2) & $\mathrm{N}$ & & & $\mathrm{x}$ & & \\
\hline Copernicia prunifera (Miller) H.E. Moore & Carnaúba & $\mathrm{N}$ & $\mathrm{x}$ & & & & \\
\hline Euterpe edulis Mart. & Palmito-juçara & $\mathrm{N}$ & $\mathrm{x}$ & & & & \\
\hline Phoenix canariensis Hort. ex Chabaud & Tamareira & $\mathrm{E}$ & & & & $\mathrm{x}$ & \\
\hline $\begin{array}{l}\text { Syagrus romanzoffiana (Cham.) Glassman } \\
\text { ASTERACEAE }\end{array}$ & Jerivá & $\mathrm{N}_{\mathrm{c}}$ & $\mathrm{x}$ & $\mathrm{x}$ & $\mathrm{x}$ & $\mathrm{x}$ & $\mathrm{x}$ \\
\hline Gochnatia polymorpha (Less.) Cabrera & Cambará & $\mathrm{N}_{\mathrm{c}}$ & & & & & $\mathrm{x}$ \\
\hline $\begin{array}{l}\text { Vernonanthura discolor (Spreng.) H. Rob. } \\
\text { BIGNONIACEAE }\end{array}$ & Vassorão-preto & $\mathrm{N}_{\mathrm{c}}$ & & $\mathrm{x}$ & & & \\
\hline Cybistax antisyphilitica (Mart.) Mart. & Ipê-verde & $\mathrm{N}$ & $\mathrm{x}$ & $\mathrm{x}$ & $\mathrm{x}$ & $\mathrm{x}$ & $\mathrm{x}$ \\
\hline Handroanthus albus (Cham.) Mattos & Ipê-amarelo-graúdo & $\mathrm{N}_{\mathrm{c}}$ & $\mathrm{x}$ & $\mathrm{x}$ & $\mathrm{x}$ & $\mathrm{x}$ & $\mathrm{x}$ \\
\hline Handroanthus chrysotrichus (Mart. ex A. DC.) Mattos & Ipê-amarelo-miúdo & $\mathrm{N}_{\mathrm{c}}$ & $\mathrm{x}$ & $\mathrm{x}$ & $\mathrm{x}$ & $\mathrm{x}$ & $\mathrm{x}$ \\
\hline Handroanthus heptaphyllus (Vell.) Mattos & Ipê-roxo & $\mathrm{N}$ & $\mathrm{x}$ & $\mathrm{x}$ & $\mathrm{x}$ & $\mathrm{x}$ & $\mathrm{x}$ \\
\hline Jacaranda mimoseafolia D. Don & Jacarandá-mimoso & $\mathrm{E}$ & $\mathrm{x}$ & & $\mathrm{x}$ & $\mathrm{x}$ & \\
\hline Jacaranda puberula Cham. & Carobinha & $\mathrm{N}_{\mathrm{c}}$ & $\mathrm{x}$ & & $\mathrm{x}$ & & $\mathrm{x}$ \\
\hline $\begin{array}{l}\text { Handroanthus sp. } \\
\text { CANELLACEAE }\end{array}$ & Ipê & & & & & $\mathrm{x}$ & \\
\hline $\begin{array}{l}\text { Cinnamodendron dinisii Schwacke } \\
\text { CELASTRACEAE }\end{array}$ & Pimenteira & $\mathrm{N}_{\mathrm{c}}$ & $\mathrm{x}$ & & $\mathrm{x}$ & & $\mathrm{x}$ \\
\hline Maytenus ilicifolia Mart. ex Reissek & Espinheira-santa & $\mathrm{N}_{\mathrm{c}}$ & $\mathrm{x}$ & & $\mathrm{x}$ & $\mathrm{x}$ & \\
\hline Maytenus sp. & Maytenus & & & & $\mathrm{x}$ & & \\
\hline CLETHRACEAE & & & & & & & \\
\hline Clethra scabra Pers. & Carne-de-vaca & $\mathrm{N}_{\mathrm{c}}$ & & & & & $\mathrm{x}$ \\
\hline
\end{tabular}




\begin{tabular}{|c|c|c|c|c|c|c|c|}
\hline \multicolumn{8}{|l|}{ CUPRESSACEAE } \\
\hline Cupressus lusitanica Mill. & Cedro & $\mathrm{E}$ & $\mathrm{x}$ & & $\mathrm{x}$ & & \\
\hline Thuja occidentalis L. & Tuia & $\mathrm{E}$ & & & & $\mathrm{x}$ & \\
\hline \multicolumn{8}{|l|}{ ERYTHROXYLACEAE } \\
\hline $\begin{array}{l}\text { Erythroxylum argentinum O.E. Schulz } \\
\text { EUPHORBIACEAE }\end{array}$ & Cocão & $\mathrm{N}_{\mathrm{c}}$ & & & & & $\mathrm{x}$ \\
\hline Alchornea glandulosa Poepp. \& Endl. & Canela-raposa & $\mathrm{N}_{\mathrm{c}}$ & & & & & $\mathrm{x}$ \\
\hline $\begin{array}{l}\text { Sebastiania commersoniana (Baill.) L.B. Sm. \& } \\
\text { Downs }\end{array}$ & Branquilho & $\mathrm{N}_{\mathrm{c}}$ & & $\mathrm{x}$ & $\mathrm{x}$ & $\mathrm{x}$ & $\mathrm{x}$ \\
\hline \multicolumn{8}{|l|}{ FABACEAE } \\
\hline Anadenanthera colubrina (Vell.) Brenan & Monjoleiro & $\mathrm{N}$ & & $\mathrm{x}$ & $\mathrm{x}$ & $\mathrm{x}$ & $\mathrm{x}$ \\
\hline Anadenanthera macrocarpa (Benth.) Brenan & Angico & $\mathrm{N}$ & $\mathrm{x}$ & $\mathrm{x}$ & & & $\mathrm{x}$ \\
\hline Ateleia glazioveana Baill. & Timbozinho & $\mathrm{N}_{\mathrm{c}}$ & & & & $\mathrm{x}$ & \\
\hline Bauhinia variegata $\mathrm{L}$. & Pata-de-vaca & $\mathrm{E}$ & $\mathrm{x}$ & $\mathrm{x}$ & $\mathrm{x}$ & $\mathrm{x}$ & \\
\hline Campomanesia guazumifolia (Cambess.) O. Berg & Sete-capotes & $\mathrm{N}_{\mathrm{c}}$ & & & & & $\mathrm{x}$ \\
\hline Cassia leptophylla Vogel & Cássia-faustosa & $\mathrm{N}$ & $\mathrm{x}$ & & $\mathrm{x}$ & $\mathrm{x}$ & $\mathrm{x}$ \\
\hline Cassia multijuga Rich. & Cássia-multijuga & $\mathrm{N}$ & $\mathrm{x}$ & $\mathrm{x}$ & & & \\
\hline Cassia $\operatorname{sp}(1)$ & Acácia (1) & & & & $\mathrm{x}$ & & \\
\hline Cassia sp (2) & Acácia (2) & & & & & $\mathrm{x}$ & \\
\hline Centrolobium robustum (Vell.) Mart. ex Benth. & Araribá & $\mathrm{N}$ & & $\mathrm{x}$ & $\mathrm{x}$ & $\mathrm{x}$ & $\mathrm{x}$ \\
\hline Dalbergia brasiliensis Vogel. & Dalbergia & $\mathrm{N}$ & & & & & $\mathrm{x}$ \\
\hline Dalbergia nigra (Vell.) Allemão ex Benth. & Dalbergia & $\mathrm{N}$ & & & $\mathrm{x}$ & & \\
\hline Enterolobium contortisiliquum (Vell.) Morong & Orelha-de-nego & $\mathrm{N}$ & $\mathrm{x}$ & & $\mathrm{x}$ & $\mathrm{x}$ & \\
\hline Erythrina falcata Benth. & Corticeira & $\mathrm{N}_{\mathrm{c}}$ & $\mathrm{x}$ & & $\mathrm{x}$ & $\mathrm{x}$ & $\mathrm{x}$ \\
\hline Erythrina speciosa Andrews & Corticeira-do-brejo & $\mathrm{N}_{\mathrm{c}}$ & $\mathrm{x}$ & $\mathrm{x}$ & $\mathrm{x}$ & $\mathrm{x}$ & \\
\hline Inga barbata Benth. & Ingá & $\mathrm{N}$ & $\mathrm{x}$ & & & & \\
\hline Inga marginata Willd. & Ingá-feijão & $\mathrm{N}$ & $\mathrm{x}$ & & $\mathrm{x}$ & $\mathrm{x}$ & $\mathrm{x}$ \\
\hline Inga sessilis (Vell.) Mart. & Ingá-macaco & $\mathrm{N}$ & $\mathrm{x}$ & & & & \\
\hline $\begin{array}{l}\text { Libidibia ferrea var. leiostachya (Benth.) L. P. } \\
\text { Queiroz }\end{array}$ & Pau-ferro & $\mathrm{N}$ & $\mathrm{x}$ & & & $\mathrm{x}$ & $\mathrm{x}$ \\
\hline Lonchocarpus sp. & Lonchocarpus & & $\mathrm{x}$ & & & & $\mathrm{x}$ \\
\hline Machaerium paraguariense Hassl. & Jacarandá-branco & $\mathrm{N}_{\mathrm{c}}$ & & & & & $\mathrm{x}$ \\
\hline Machaerium stipitatum (DC.) Vogel & Sapuva (1) & $\mathrm{N}_{\mathrm{c}}$ & & & & $\mathrm{x}$ & $\mathrm{x}$ \\
\hline Macharerium brasiliense Vogel & Sapuva (2) & $\mathrm{N}_{\mathrm{c}}$ & & & $\mathrm{x}$ & & \\
\hline Mimosa scabrella Benth. & Bracatinga & $\mathrm{N}_{\mathrm{c}}$ & & $\mathrm{x}$ & & $\mathrm{x}$ & \\
\hline Parapiptadenia rigida Benth. (Brenan) & Angico & $\mathrm{N}$ & $\mathrm{x}$ & $\mathrm{x}$ & $\mathrm{x}$ & $\mathrm{x}$ & \\
\hline Peltophorum dubium (Spreng.) Taub. & Canafístula & $\mathrm{N}$ & $\mathrm{x}$ & $\mathrm{x}$ & & $\mathrm{x}$ & \\
\hline $\begin{array}{l}\text { Poincianella pluviosa var. peltophoroides (Benth.) } \\
\text { L.P. Queiroz }\end{array}$ & Sibipiruna & $\mathrm{N}$ & $\mathrm{x}$ & & & $\mathrm{x}$ & \\
\hline Schizolobium parayba (Vell.) Blake & Guapuruvu & $\mathrm{N}$ & $\mathrm{x}$ & & & & \\
\hline Senna macranthera (DC. ex Coll.) Irwin \& Barn. & Chuva-de-ouro & $\mathrm{N}$ & $\mathrm{x}$ & $\mathrm{x}$ & $\mathrm{x}$ & $\mathrm{x}$ & \\
\hline Senna sp. & Senna sp. & & & & & $\mathrm{x}$ & \\
\hline Tipuana tipu (Benth.) Kuntze & Tipuana & $\mathrm{E}$ & $\mathrm{x}$ & $\mathrm{x}$ & $\mathrm{x}$ & $\mathrm{x}$ & $\mathrm{x}$ \\
\hline $\begin{array}{l}\text { Castanea sativa Mill. } \\
\text { LAMIACEAE }\end{array}$ & Castanha-portuguesa & $\mathrm{E}$ & & & $\mathrm{x}$ & & \\
\hline Vitex megapotamica (Spreng.) Moldenke & Tarumã (1) & $\mathrm{N}_{\mathrm{c}}$ & & & $\mathrm{x}$ & & $\mathrm{x}$ \\
\hline Vitex montevidensis Cham. & Tarumã (2) & $\mathrm{N}$ & $\mathrm{x}$ & & & & \\
\hline LAURACEAE & & & & & & & \\
\hline Cinnamomum sellowianum (Nees \& Mart.) Kosterm. & Canela-raposa & $\mathrm{N}_{\mathrm{c}}$ & & & & & $\mathrm{x}$ \\
\hline Cinnamomum vesiculosum (Nees) Kosterm. & Canela-alho & $\mathrm{N}_{\mathrm{c}}$ & & & & & $\mathrm{x}$ \\
\hline Cryptocarya aschersoniana $\mathrm{Mez}$ & Canela-fogo & $\mathrm{N}$ & & & $\mathrm{x}$ & & \\
\hline Nectandra lanceolata Ness & Canela-amarela & $\mathrm{N}_{\mathrm{c}}$ & & & $\mathrm{x}$ & & \\
\hline Nectandra megapotamica (Spreng.) Mez & Canela-imbuiá & $\mathrm{N}_{\mathrm{c}}$ & $\mathrm{x}$ & & & & \\
\hline Ocotea porosa (Nees \& Mart.) Barroso & Imbuiá & $\mathrm{N}_{\mathrm{c}}$ & & & $\mathrm{x}$ & & \\
\hline Ocotea puberula (Rich.) Nees & Canela-guaicá & $\mathrm{N}_{\mathrm{c}}$ & $\mathrm{x}$ & & $\mathrm{x}$ & & $\mathrm{x}$ \\
\hline
\end{tabular}




\begin{tabular}{|c|c|c|c|c|c|c|c|}
\hline \multirow{2}{*}{$\begin{array}{l}\text { Ocotea pulchella (Nees \& Mart.) Mez. } \\
\text { Persea americana Mill. }\end{array}$} & \multirow{2}{*}{$\begin{array}{l}\text { Canela-lageana } \\
\text { Abacateiro }\end{array}$} & \multicolumn{3}{|l|}{$\mathrm{N}_{\mathrm{c}}$} & & & $\mathrm{x}$ \\
\hline & & $\mathrm{E}$ & & & $\mathrm{x}$ & & \\
\hline LAXMANNIACEAE & & & & & & & \\
\hline $\begin{array}{l}\text { Cordyline spectabilis Kunth \& Bouché } \\
\text { LECYTHIDACEAE }\end{array}$ & Uvarana & $\mathrm{N}_{\mathrm{c}}$ & & & $\mathrm{x}$ & & $\mathrm{x}$ \\
\hline $\begin{array}{l}\text { Couroupita guianensis Aubl. } \\
\text { LYTRACEAE }\end{array}$ & Abricó & $\mathrm{N}$ & & & $\mathrm{x}$ & & \\
\hline Lafoensia pacari A. St.-Hil. & Dedaleiro & $\mathrm{N}_{\mathrm{c}}$ & $\mathrm{x}$ & $\mathrm{x}$ & $\mathrm{x}$ & $\mathrm{x}$ & $\mathrm{x}$ \\
\hline $\begin{array}{l}\text { Lagerstroemia indica } \mathrm{L} \text {. } \\
\text { MAGNOLIACEAE }\end{array}$ & Extremosa & $\mathrm{E}$ & $\mathrm{x}$ & & & & \\
\hline Magnolia grandiflora $\mathrm{L}$. & Magnólia-branca & $\mathrm{E}$ & $\mathrm{x}$ & & $\mathrm{x}$ & & \\
\hline Michelia champaca $\mathrm{L}$. & Magnólia-amarela & $\mathrm{E}$ & $\mathrm{x}$ & & & & \\
\hline MALVACEAE & & & & & & & \\
\hline Chorisia speciosa A. St.-Hil. & Paineira & $\mathrm{N}$ & $\mathrm{x}$ & $\mathrm{x}$ & $\mathrm{x}$ & $\mathrm{x}$ & $\mathrm{x}$ \\
\hline Pseudobombax sp. & Embira & & $\mathrm{x}$ & & & & \\
\hline MELASTOMATACEAE & & & & & & & \\
\hline Tibouchina granulosa (Desr.) Cogn. & Quaresmeira-granulosa & $\mathrm{N}$ & & & & $\mathrm{x}$ & \\
\hline Tibouchina mutabilis (Vell.) Cong. & Quaresmeira & $\mathrm{N}$ & $\mathrm{x}$ & & $\mathrm{x}$ & & $\mathrm{x}$ \\
\hline Tibouchina pulchra Cong. & Jacatirão & $\mathrm{N}$ & $\mathrm{x}$ & & & & \\
\hline MELIACEAE & & & & & & & \\
\hline Cedrela fissilis Vell. & Cedro & $\mathrm{N}_{\mathrm{c}}$ & $\mathrm{x}$ & & $\mathrm{x}$ & & \\
\hline Melia azedarach $\mathrm{L}$. & Cinamomo & $\mathrm{E}$ & $\mathrm{x}$ & $\mathrm{x}$ & $\mathrm{x}$ & $\mathrm{x}$ & \\
\hline $\begin{array}{l}\text { Toona sinensis (A. Juss.) M. Roem. } \\
\text { MORACEAE }\end{array}$ & Toona & $\mathrm{E}$ & & & $\mathrm{x}$ & & \\
\hline Ficus enormis (Mart. ex Miq.) Mart. & Figueira & $\mathrm{E}$ & $\mathrm{x}$ & $\mathrm{x}$ & & & \\
\hline Ficus sp.(1) & Figueira (1) & & $\mathrm{x}$ & $\mathrm{x}$ & & & \\
\hline Ficus sp.(2) & Figueira (2) & & $\mathrm{x}$ & & & & \\
\hline Ficus sp.(3) & Figueira (3) & & $\mathrm{x}$ & & & & \\
\hline Ficus sp.(4) & Figueira (4) & & $\mathrm{x}$ & & & & $\mathrm{x}$ \\
\hline $\begin{array}{l}\text { Morus nigra } \mathrm{L} . \\
\text { MYRCINACEAE }\end{array}$ & Amoreira & $\mathrm{E}$ & $\mathrm{x}$ & $\mathrm{x}$ & $\mathrm{x}$ & $\mathrm{x}$ & $\mathrm{x}$ \\
\hline $\begin{array}{l}\text { Myrsine coriaceae (Sw.) R. Br. ex Roem. \& Schult. } \\
\text { MYRTACEAE }\end{array}$ & Capororoca & $\mathrm{N}_{\mathrm{c}}$ & & $\mathrm{x}$ & $\mathrm{x}$ & $\mathrm{x}$ & \\
\hline Campomanesia xanthocarpa Mart. O. Berg & Guabiroba & $\mathrm{N}_{\mathrm{c}}$ & $\mathrm{x}$ & $\mathrm{x}$ & $\mathrm{x}$ & $\mathrm{x}$ & $\mathrm{x}$ \\
\hline Eucalyptus grandis W. Mill ex Maiden & Eucalipto (1) & $\mathrm{E}$ & $\mathrm{x}$ & $\mathrm{x}$ & $\mathrm{x}$ & $\mathrm{x}$ & \\
\hline Eucalyptus robusta $\mathrm{Sm}$. & Eucalipto (2) & $\mathrm{E}$ & $\mathrm{x}$ & & & & \\
\hline Eucalyptus sp. & Eucalipto (3) & $\mathrm{E}$ & $\mathrm{x}$ & & & & \\
\hline Eucalyptus viminalis Hook. & Eucalipto (4) & $\mathrm{E}$ & $\mathrm{x}$ & & & & \\
\hline Eugenia uniflora $\mathrm{L}$. & Pitanga & $\mathrm{N}_{\mathrm{c}}$ & $\mathrm{x}$ & $\mathrm{x}$ & $\mathrm{x}$ & $\mathrm{x}$ & $\mathrm{x}$ \\
\hline Myrcea selloi (Spreng) N. Silveira & Cambuí-preto & $\mathrm{N}_{\mathrm{c}}$ & & & & & $\mathrm{x}$ \\
\hline Myrceugenia sp. & Cambuí & & & $\mathrm{x}$ & $\mathrm{x}$ & & \\
\hline Myrceugenia euosma (O. Berg) D. Legrand & Guamirim & $\mathrm{N}_{\mathrm{c}}$ & & & $\mathrm{x}$ & & $\mathrm{x}$ \\
\hline Myrcia rostrata DC. & Guamirim-chorão & $\mathrm{N}_{\mathrm{c}}$ & & & & & $\mathrm{x}$ \\
\hline Psidium araça Raddi. & Araçá & $\mathrm{N}_{\mathrm{c}}$ & $\mathrm{x}$ & $\mathrm{x}$ & $\mathrm{x}$ & $\mathrm{x}$ & $\mathrm{x}$ \\
\hline Psidium cattleianum Sabine & Araçá-rosa & $\mathrm{N}$ & & & & $\mathrm{x}$ & \\
\hline $\begin{array}{l}\text { Psidium guayava L. } \\
\text { NYCTAGINACEAE }\end{array}$ & Goiabeira & $\mathrm{N}$ & $\mathrm{x}$ & $\mathrm{x}$ & $\mathrm{x}$ & & \\
\hline $\begin{array}{l}\text { Bougainvillea glabra Choisy } \\
\text { OLEACEAE }\end{array}$ & Primavera & $\mathrm{N}_{\mathrm{c}}$ & $\mathrm{x}$ & & & & \\
\hline $\begin{array}{l}\text { Ligustrum lucidum W.T. Aiton. } \\
\text { PINACEAE }\end{array}$ & Alfeneiro & $\mathrm{E}$ & $\mathrm{x}$ & $\mathrm{x}$ & $\mathrm{x}$ & $\mathrm{x}$ & $\mathrm{x}$ \\
\hline Pinus sp. & Pinus (1) & $\mathrm{E}$ & $\mathrm{x}$ & & $\mathrm{x}$ & & \\
\hline Pinus elliottii Engelm. & Pinus (2) & $\mathrm{E}$ & & $\mathrm{x}$ & & & \\
\hline
\end{tabular}




\begin{tabular}{|c|c|c|c|c|c|c|c|}
\hline \multicolumn{8}{|l|}{ PITTOSPORACEAE } \\
\hline $\begin{array}{l}\text { Pittosporum undulatum Vent. } \\
\text { PLATANACEAE }\end{array}$ & Pau-incenso & $\mathrm{E}$ & $\mathrm{x}$ & $\mathrm{x}$ & $\mathrm{x}$ & & $\mathrm{x}$ \\
\hline $\begin{array}{l}\text { Platanus acerifolia (Aiton) Willd. } \\
\text { PODOCARPACEAE }\end{array}$ & Plátanus & $\mathrm{E}$ & $\mathrm{x}$ & & $\mathrm{x}$ & & \\
\hline $\begin{array}{l}\text { Podocarpus lambertii Klotzsch ex Endl. } \\
\text { PROTEACEAE }\end{array}$ & Pinheiro-bravo & $\mathrm{N}_{\mathrm{c}}$ & $\mathrm{x}$ & $\mathrm{x}$ & $\mathrm{x}$ & $\mathrm{x}$ & $\mathrm{x}$ \\
\hline Grevillea robusta A. Cunn. ex R. Br. L.H. Bailey & Grevílea & $\mathrm{E}$ & & & $\mathrm{x}$ & $\mathrm{x}$ & \\
\hline $\begin{array}{l}\text { Roupala brasiliensis Klotzsch } \\
\text { RHAMNACEAE }\end{array}$ & Carvalho & $\mathrm{N}_{\mathrm{c}}$ & $\mathrm{x}$ & & & & $\mathrm{x}$ \\
\hline $\begin{array}{l}\text { Hovenia dulcis Thunb. } \\
\text { ROSACEAE }\end{array}$ & Uva-do-japão & $\mathrm{E}$ & & & $\mathrm{x}$ & & \\
\hline Eriobotrya japonica (Thunb.) Lindl. & Amexeira-amarela & $\mathrm{E}$ & & $\mathrm{x}$ & $\mathrm{x}$ & & \\
\hline $\begin{array}{l}\text { Prunus brasiliensis (Cham. \& Schltdl.) D. Dietr. } \\
\text { RUTACEAE }\end{array}$ & Pessegueiro-bravo & $\mathrm{N}_{\mathrm{c}}$ & $\mathrm{x}$ & & & & $\mathrm{x}$ \\
\hline Citrus limon (L.) Burm. f. & Limoeiro & $\mathrm{E}$ & & & & $\mathrm{x}$ & \\
\hline Pilocarpus pennatifolius Lem. & Jaborandi & $\mathrm{N}$ & $\mathrm{x}$ & & & & \\
\hline $\begin{array}{l}\text { Zanthoxyllum rhoifolium Lam. } \\
\text { SALICACEAE }\end{array}$ & Mamica-de-porca & $\mathrm{N}_{\mathrm{c}}$ & $\mathrm{x}$ & & & & \\
\hline Populus nigra L. & Álamo & $\mathrm{E}$ & $\mathrm{x}$ & & & $\mathrm{x}$ & \\
\hline Salix babylonica $\mathrm{L}$. & Chorão & $\mathrm{E}$ & & & & $\mathrm{x}$ & \\
\hline Salix nigra Marshall & Chorão-piramidal & $\mathrm{E}$ & & & & $\mathrm{x}$ & \\
\hline $\begin{array}{l}\text { Xylosma G. Forst. } \\
\text { SAPINDACEAE }\end{array}$ & Sucará & & & & & & $\mathrm{x}$ \\
\hline Acer palmatum Raf. & Acer-palmado & $\mathrm{E}$ & & & $\mathrm{x}$ & & \\
\hline Allophylus edulis (A.St.-Hil. et al.) Hieron. ex Niederl. & Vacum & $\mathrm{N}_{\mathrm{c}}$ & $\mathrm{x}$ & $\mathrm{x}$ & $\mathrm{x}$ & $\mathrm{x}$ & $\mathrm{x}$ \\
\hline Cupania vernalis Cambess. & Cuvatã & $\mathrm{N}_{\mathrm{c}}$ & $\mathrm{x}$ & $\mathrm{x}$ & & & \\
\hline Koelreuteria paniculata Laxm. & Coeleutéria & $\mathrm{E}$ & $\mathrm{x}$ & & $\mathrm{x}$ & $\mathrm{x}$ & \\
\hline $\begin{array}{l}\text { Matayba elaeagnoides Radlk. } \\
\text { SAPOTACEAE }\end{array}$ & Miguel-pintado & $\mathrm{N}$ & & $\mathrm{x}$ & $\mathrm{x}$ & & \\
\hline $\begin{array}{l}\text { Chrysophyllum gonocarpum (Mart. \& Eichler ex } \\
\text { Miq.) Engl. }\end{array}$ & Peroba-branca & $\mathrm{N}$ & & & $\mathrm{x}$ & & \\
\hline $\begin{array}{l}\text { Crisophyllum sp. } \\
\text { SOLANACEAE }\end{array}$ & Aguaí & & $\mathrm{x}$ & & & & \\
\hline $\begin{array}{l}\text { Solanum sanctae-catharinae Dunal } \\
\text { STERCULIACEAE }\end{array}$ & Peloteira & $\mathrm{N}_{\mathrm{c}}$ & & & & & $\mathrm{x}$ \\
\hline $\begin{array}{l}\text { Guasuma ulmifolia Lam. } \\
\text { STYRACACEAE }\end{array}$ & Periquiteira & $\mathrm{N}$ & & & $\mathrm{x}$ & $\mathrm{x}$ & $\mathrm{x}$ \\
\hline Styrax sp. & Benjoeiro & & & & & & $\mathrm{x}$ \\
\hline $\begin{array}{l}\text { Styrax leprosus Hook. \& Arn. } \\
\text { TAXODIACEAE }\end{array}$ & Canela-seiva & $\mathrm{N}_{\mathrm{c}}$ & & & & & $\mathrm{x}$ \\
\hline Sequoia sempervirens (D. Don) Endl. & Sequoia & $\mathrm{E}$ & & & & $\mathrm{x}$ & \\
\hline $\begin{array}{l}\text { Taxodium distichum (L.) Kunth } \\
\text { TILIACEAE }\end{array}$ & Pinheiro-do-brejo & $\mathrm{E}$ & & $\mathrm{x}$ & $\mathrm{x}$ & $\mathrm{x}$ & \\
\hline $\begin{array}{l}\text { Luehea divaricata Mart. \& Zucc. } \\
\text { VERBENACEAE }\end{array}$ & Açoita-cavalo & $\mathrm{N}_{\mathrm{c}}$ & $\mathrm{x}$ & $\mathrm{x}$ & $\mathrm{x}$ & $\mathrm{x}$ & $\mathrm{x}$ \\
\hline Cytharexylum mirianthum Cham. & Tarumã-branco & $\mathrm{N}$ & & & & $\mathrm{x}$ & \\
\hline Citharexylum rigidum (Briq.) Moldenke & Jataúva & $\mathrm{N}$ & $\mathrm{x}$ & & & & \\
\hline
\end{tabular}

Nota: O: origem: E: exótica; N: nativa; $\mathrm{N}_{\mathrm{c}}$ : nativa de Curitiba; (1) Passeio Público; (2) Parque Bacacheri; (3) Parque São Lourenço; (4) Parque Municipal Barigui; (5) Parque Municipal do Passaúna.

O maior número de indivíduos/espécie foi Schinus terebinthifolius (aroeira-vermelha), com 463 indivíduos distribuídos nos parques Passaúna (307 indivíduos com 294 adultos) e São Lourenço (62 indivíduos com 57 jovens). Em seguida veio Tipuana tipu (tipuana), com 380 indivíduos distribuídos nos parques Barigui (268 indivíduos adultos) e São Lourenço (57 indivíduos com 54 jovens). E em 
terceiro lugar, Syagrus romanzoffiana (jerivá), com 271 indivíduos, distribuídos no Passeio Público (84 indivíduos, com 58 adultos) e no Parque Bacacheri (62 indivíduos com 56 jovens).

A predominância de aroeira-vermelha e jerivá no paisagismo das áreas verdes justifica-se por serem espécies nativas do ecossistema de Curitiba, ajudando assim a valorizar e preservar a flora local. $\mathrm{O}$ enriquecimento das áreas verdes urbanas com espécies nativas de caráter paisagístico representa um aumento de valorização, contribuindo, em parte, para a conservação dessas espécies (GUIA et al., 2008).

Mielke (2012) enfatiza o empenho da Prefeitura Municipal de Curitiba pela manutenção de áreas verdes, particulares e públicas, sendo que Parques e Bosques Municipais (UCs) representam aproximadamente 5\% do remanescente de Floresta Ombrófila Mista (313 ha).

A predominância de Tipuana tipu (tipuana) no Parque Municipal Barigui e no Parque São Lourenço pode ser devido à alta produção de mudas dessas espécies na década de 70 pela Prefeitura de Curitiba (BIONDI; ALTHAUS, 2005), o que coincide com a década de criação dos parques.

Das 149 espécies encontradas, 56 são nativas de Curitiba, 38 são nativas do Brasil, 37 são exóticas e 18 foram identificados até gênero. Observa-se que mais de $60 \%$ das espécies são nativas do Brasil, sendo que 38\% são espécies nativas de Curitiba. Embora a época de criação dos parques analisados seja distinta e consequentemente com objetivos variados, a manutenção da vegetação nos remanescentes florestais dessas áreas e o uso de espécies nativas no paisagismo segue, na sua maioria, a linha projetual do paisagismo moderno e contemporâneo, com exceção do Passeio Público, que seguiu a linha eclética. Para Macedo (1999), a linha do paisagismo moderno objetiva a criação de novos espaços que se identifiquem com a paisagem local, além do apelo nacionalista. Dentre as características da linha projetual contemporânea dos parques urbanos citados por Macedo e Sakata (2010), observa-se que o uso da vegetação também apresenta a ideologia de preservação dos ecossistemas locais.

Segundo Ziller e Zalba (2007), a expressão espécie nativa refere-se às espécies dentro dos limites de sua distribuição natural em termos evolutivos, ou seja, a limites ambientais e não políticos. Espécies movidas de um ecossistema a outro, dentro de um país, são tão exóticas quanto espécies não nacionais e também apresentam um alto potencial de risco e dano.

Segundo a Portaria IAP $n^{\circ}$ 095/2007 (PARANÁ, 2007), Psidium guajava (goiabeira), embora seja uma espécie nativa, é considerada espécie invasora. Essa espécie foi encontrada em três parques: Passeio Público, Parque Bacacheri e Parque São Lourenço.

Das 37 espécies exóticas encontradas, 13 são espécies exóticas invasoras distribuídas em 9 famílias, segundo a Portaria IAP n ${ }^{\circ}$ 095/2007 (PARANÁ, 2007) e o Decreto n ${ }^{\circ}$ 473/2008 da Prefeitura Municipal de Curitiba (CURITIBA, 2008). Observa-se que o número de espécies exóticas invasoras é alto, considerando suas diferentes características e consequentemente as dificuldades para viabilizar os meios de erradicação e controle.

Assim, o ideal seria realizar inventários arbóreos contínuos para acompanhar a dinâmica dessas espécies. DeCandido (2004) exemplifica a dinâmica de espécies exóticas num parque urbano em Nova York, EUA, constatando que, no período de 1947 a 1994, foram perdidos 25,5\% das espécies nativas, ou uma taxa de 2,9 espécies por ano. Complementa ainda que a flora nativa caiu de 71,7\% em 1947 para 59,6\% em 1994-98.

Do total de espécies exóticas invasoras, apenas duas ocorrem em um só parque: Hovenia dulcis (uvado-japão), no Parque São Lourenço, e Pinus sp. (pínus), no Parque Bacacheri. Já Ligustrum lucidum (alfeneiro) e Morus nigra (amoreira) ocorrem nos 5 parques. A ocorrência de espécies invasoras em um só parque pode ser um aspecto facilitador para a execução do controle dessas espécies. Maior detalhamento do número de indivíduos adultos e jovens de cada área verde por origem das espécies é apresentado na tabela 2.

Tabela 2. Número de indivíduos adultos e jovens por origem das espécies nos parques analisados. Table 2. Number of adults and young by species origin in the analyzed parks.

\begin{tabular}{|c|c|c|c|c|c|c|c|c|c|c|c|c|}
\hline \multirow{3}{*}{ Áreas verdes } & \multicolumn{3}{|c|}{ E. N. Brasil } & \multicolumn{3}{|c|}{ E. N. Curitiba } & \multicolumn{3}{|c|}{ E. Exótica } & \multicolumn{3}{|c|}{ E. E. Invasora } \\
\hline & \multirow{2}{*}{$\begin{array}{c}\text { SP } \\
\mathbf{N}\end{array}$} & \multicolumn{2}{|c|}{ Indiv. } & \multirow{2}{*}{$\begin{array}{c}\text { SP } \\
N\end{array}$} & \multicolumn{2}{|c|}{ Indiv. } & \multirow{2}{*}{$\begin{array}{c}\mathbf{S P} \\
\mathbf{N} \\
\end{array}$} & \multirow{2}{*}{\multicolumn{2}{|c|}{$\begin{array}{rr} & \text { Indiv. } \\
\text { A } & \text { J } \\
\end{array}$}} & \multirow{2}{*}{$\begin{array}{l}\mathbf{S P} \\
\mathbf{N} \\
\end{array}$} & \multicolumn{2}{|c|}{ Indiv. } \\
\hline & & $\mathbf{A}$ & $\mathbf{J}$ & & $\mathbf{A}$ & $\mathbf{J}$ & & & & & $\mathbf{A}$ & $\mathbf{J}$ \\
\hline Passeio Público & 25 & 255 & 91 & 27 & 302 & 119 & 13 & 183 & 14 & 10 & 45 & 2 \\
\hline Parque Bacacheri & 22 & 22 & 58 & 20 & 144 & 104 & 4 & 7 & 37 & 7 & 11 & 13 \\
\hline Parque São Lourenço & 18 & 27 & 198 & 30 & 129 & 435 & 13 & 20 & 138 & 8 & 5 & 58 \\
\hline Parque Municipal Barigui & 17 & 259 & 81 & 22 & 317 & 130 & 11 & 491 & 7 & 5 & 10 & 1 \\
\hline Parque Municipal Passaúna & 12 & 75 & 0 & 40 & 1229 & 150 & 1 & 9 & 0 & 3 & 6 & 0 \\
\hline
\end{tabular}

Nota: E. N. Brasil: espécie nativa do Brasil; E. N. Curitiba: espécie nativa de Curitiba; E. Exótica: espécie exótica; E. E. Invasora: espécie exótica invasora; SP/N: número de espécies; Indiv./A: número de indivíduos adultos; Indiv./J: número de indivíduos jovens. 
Pode-se observar, na tabela 2, que o Passeio Público foi o parque que apresentou maior número de espécies exóticas (13 espécies) e exóticas invasoras (10 espécies). A utilização de espécies exóticas nas áreas verdes no século 19 tinha forte influência europeia. De acordo com Macedo (1999), nessa época dominava no Brasil o ecletismo, linha projetual paisagística caracterizada pela criação de cenários semelhantes aos das metrópoles europeias. Além disso, a utilização de espécies exóticas pode também ser justificada pela função primitiva do parque. Segundo Nogueira (2010), durante o século 19, essa área verde foi, por um tempo, o primeiro Jardim Botânico de Curitiba, e depois o primeiro zoológico de Curitiba, até 1982. Quando uma área verde funciona como Jardim Botânico, necessita de uma grande variedade de espécies nativas e exóticas para compor uma coleção de espécies $e x$-situ, que, de acordo com o Plano de Ação para os Jardins Botânicos Brasileiros (2004), é requisito para a conservação da diversidade biológica dos jardins botânicos nacionais.

Rotta et al. (2004), analisando as árvores do Passeio Público, afirmaram que a diversidade de espécies desse parque tem um grande valor educativo, porque parece com um jardim botânico. Afirmaram ainda que existem exemplares de Platanus acerifolia (plátanos) que ultrapassam os 90 anos de idade, provavelmente sendo ainda remanescentes da época da sua inauguração, constituindo um referencial incorporado à história do Passeio Público e de Curitiba.

Vale salientar que o Parque São Lourenço também apresentou o mesmo número de espécies exóticas do Passeio Público (13 espécies), o que pode ter sido decorrente da influência do uso e ocupação do solo anterior à criação do parque - um curtume e fábrica de cola.

O Parque Municipal do Passaúna apresentou maior número de espécies nativas de Curitiba (40) e de indivíduos adultos (1229). Por outro lado, apresentou menor número de espécies nativas do Brasil (12) e nenhum indivíduo jovem. Embora esse parque tenha sofrido intervenções paisagísticas em função das infraestruturas criadas (trilha, quiosques com churrasqueiras, trapiches, pontes, mirantes e outros), observa-se que a grande maioria das espécies que se encontram isoladas ou em pequenos agrupamentos ladeando o grande lago e trilhas - são remanescentes do local (nativas do ecossistema de Curitiba). Sendo assim, acredita-se que grande parte das espécies nativas de Curitiba remanescentes na área foi aproveitada no paisagismo do parque. Esse resultado pode se apoiar no levantamento de Biondi e Leal (2008), no qual afirmam que até 2008 o Horto Municipal de Curitiba, que abastece as espécies arbóreas no paisagismo das áreas verdes, produzia principalmente espécies nativas do Brasil $(56,97 \%)$, enquanto que o número de espécies nativas da cidade de Curitiba ainda era pequeno (26,67\%).

Com base na Portaria IAP n ${ }^{\circ}$ 095/2007 (PARANÁ, 2007) e no Decreto n ${ }^{\circ} 473 / 2008$ da Prefeitura Municipal de Curitiba (CURITIBA, 2008), juntamente com as informações das tabelas 1 e 2, foram observadas as seguintes espécies exóticas invasoras nos parques: (a) Citrus limon (limoeiro), fam. Rutaceae - com apenas um indivíduo adulto no Parque Municipal Barigui; (b) Eriobotrya japonica (ameixeira-amarela), fam. Rosaceae - com 3 indivíduos adultos e 2 jovens no Parque Bacacheri e 4 jovens no Parque São Lourenço; (c) Eucalyptus grandis (eucalipto), fam. Myrtaceae - com 1 indivíduo adulto no Passeio Público, 1 jovem no Parque São Lourenço e 3 adultos no Parque Municipal Barigui; (d) Eucalyptus robusta (eucalipto), fam. Myrtaceae - com 6 indivíduos adultos no Passeio Público; (e) Eucalyptus sp. (eucalipto), fam. Myrtaceae - com 4 indivíduos adultos no Passeio Público; (f) Eucalyptus viminalis (eucalipto), fam. Myrtaceae - com 5 indivíduos adultos no Passeio Público; (g) Hovenia dulcis (uva-do-japão), fam. Rhamnaceae - com 10 indivíduos jovens no Parque São Lourenço; Ligustrum lucidum (alfeneiro), fam. Oleaceae - ocorre em todos os parques, sendo 12 indivíduos adultos no Passeio Público, 6 adultos e 3 jovens no Parque Bacacheri, 23 jovens no Parque São Lourenço, 2 adultos no Parque Municipal Barigui e 1 adulto no Parque Municipal do Passaúna; (h) Melia azedarach (cinamomo), fam. Meliaceae - com 2 indivíduos adultos e 1 jovem no Passeio Público, 1 adulto e 3 jovens no Parque Bacacheri, 1 adulto e 2 jovens no Parque São Lourenço e 3 adultos e 1 jovem no Parque Municipal Barigui; (i) Morus nigra (amoreira), fam. Moraceae - com 1 indivíduo adulto e 1 jovem no Passeio Público, 1 jovem no Parque Bacacheri, 3 adultos no Parque São Lourenço, 1 adulto no Parque Municipal Barigui e 2 adultos no Parque Municipal do Passaúna; (j) Pinus elliottii (pínus), fam. Pinaceae - com 1 indivíduo adulto no Parque Bacacheri; (l) Pinus sp.(pínus), fam. Pinaceae - com 13 indivíduos adultos no Passeio Público e um indivíduo jovem no Parque São Lourenço; (m) Pittosporum undulatum (pauincenso), fam. Pittosporaceae - com 1 indivíduo adulto no Passeio Público, 3 jovens no Parque Bacacheri, 18 jovens no Parque São Lourenço e 3 adultos no Parque Municipal do Passaúna. 
A ocorrência de espécies exóticas invasoras na fase adulta nos parques pode indicar que elas já existiam antes da criação do parque e/ou da legislação de proibição dessas espécies. Nessa fase, a espécie pode ser uma ameaça constante, não só para o paisagismo local, mas também para os fragmentos florestais remanescentes do parque e/ou áreas adjacentes, devido à dispersão de suas sementes. Já a ocorrência das espécies invasoras na fase jovem pode estar indicando o efeito das espécies adultas ou o desconhecimento dos responsáveis pelo tratamento paisagístico. Isso também pode indicar a falta de manutenção da vegetação de áreas de uso intensivo do parque, tais como estacionamento, proximidade às trilhas ou caminhos, lago e construções.

Para alguns autores, o controle mais efetivo das espécies exóticas é realizado quando elas se encontram em estágio jovem. Mack et al. (2000) e Burt et al. (2007) indicam que é melhor a prevenção de introduções iniciais, forma mais efetiva de evitar gastos associados com o combate de plantas invasoras, ao invés de controle subsequente ou erradicação. Ziller e Zalba (2007) afirmam que, entre as ações para evitar e resolver problemas relacionados às espécies invasoras, está o não cultivo de plantas ornamentais exóticas invasoras e a não utilização de espécies exóticas em projetos de restauração ambiental.

As espécies exóticas invasoras que apresentaram o maior número de indivíduos nos parques foram: alfeneiro (47), pau-incenso (25) e pínus (13).

O alfeneiro é uma das espécies mais frequentes não só nas áreas verdes como também na arborização de ruas, tendo sido introduzida voluntariamente para fins ornamentais. Mielke (2012) encontrou 2196 indivíduos de alfeneiro em 18 Unidades de Conservação da cidade de Curitiba e afirmou que foi a espécie exótica invasora mais frequente. Silva et al. (2007b) diz que essa espécie é uma das mais comuns na arborização de ruas nos estados do sul do Brasil. Milano (1984), em inventário de árvores, apontou o alfeneiro como uma das três espécies mais frequentes na arborização de ruas de Curitiba. Bobrowski (2012), em reanálise desse inventário, cita que o alfeneiro ainda continua na lista de espécies mais frequentes nas ruas de Curitiba. Conforme Ziller et al. (2004), essa espécie tornou-se invasora em ambientes urbanos e na Floresta Ombrófila Mista. Segundo Silva et al. (2007a), a sua dispersão e seu crescimento ocorrem de maneira rápida, fazendo-a competir e impedir a regeneração de plantas nativas.

Quanto à frequência do pau-incenso e pínus, segundo Mielke (2012), essas espécies, juntamente com eucalipto, amora e uva-do-japão, são as árvores exóticas invasoras mais frequentes e abundantes em 22 Unidades de Conservação de Curitiba. Afirma ainda que a incidência de árvores exóticas invasoras em Curitiba é afetada pela jardinagem e paisagismo e por áreas circunvizinhas de reflorestamento.

Lima Neto et al. (2011), analisando as características das espécies arbóreas nas áreas verdes públicas de Aracaju (SE), constataram, entre outros problemas, a presença de espécies exóticas invasoras, que gerou grande preocupação por conta da perda de biodiversidade, pois elas limitam o desenvolvimento de outras espécies, seja por sombreamento ou mesmo por provocar extinção de determinadas espécies em vários ambientes.

As espécies Citrus limon, Eriobotrya japonica, Eucalyptus grandis, Eucalyptus robusta, Eucalyptus viminalis, Eucalyptus sp., Hovenia dulcis, Ligustrum lucidum, Melia azedarach, Morus nigra, Pinus elliottii, Pinus sp. e Pittosporum undulatum estão na lista oficial de espécies exóticas invasoras para o estado do Paraná, e Eucalyptus viminalis, Eucalyptus sp., Hovenia dulcis, Ligustrum lucidum, Melia azedarach, Morus nigra, Pinus elliottii, Pinus sp. e Pittosporum undulatum estão na lista oficial de espécies exóticas invasoras para o município de Curitiba. Isso indica que o número de espécies exóticas invasoras encontradas nos parques representa $100 \%$ da lista definida pelo município de Curitiba e 23,4\% da lista oficial para o estado do Paraná. Sendo assim, essas duas instâncias político-administrativas têm o compromisso de adotar medidas preventivas, de erradicação e de controle dessas espécies nos referidos locais públicos, a fim de conservar os remanescentes de floresta existentes.

\section{CONCLUSÕES}

- Com a identificação das árvores em nível de gênero e espécie, pode-se concluir que o paisagismo dos cinco parques analisados é caracterizado por uma diversidade de 149 espécies arbóreas numa população de 5525 indivíduos, das quais $38,25 \%$ são nativas do ecossistema de Curitiba, 24,83\% são espécies nativas do Brasil e 24,83\% são espécies exóticas. 
- Apenas 7 famílias representam 50\% das 48 famílias encontradas, com predominância da Fabaceae $(20,8 \%)$, sendo que o maior número de famílias verificou-se no Parque São Lourenço.

- O maior número de espécies nativas de Curitiba foi observado no Parque Municipal do Passaúna, seguido pelo Parque São Lourenço, Passeio Público, Parque Municipal Barigui e Parque Bacacheri.

- As espécies que apresentaram o maior número de indivíduos nos parques foram: Schinus terebinthifolius (aroeira-vermelha), no Parque Municipal do Passaúna e Parque São Lourenço, Tipuana tipu (tipuana), no Parque Municipal Barigui e Parque São Lourenço, e Syagrus romanzoffiana (jerivá) no Passeio Público e Parque Bacacheri.

- De 37 espécies exóticas que ocorrem nos parques, 13 são invasoras (35,13\%), segundo a Portaria IAP $\mathrm{n}^{\circ}$ 095/2007 (PARANÁ, 2007) e o Decreto ${ }^{\circ}$ 473/2008 da Prefeitura Municipal de Curitiba (CURITIBA, 2008). Essas espécies estão distribuídas em 9 famílias botânicas, que apresentam comportamentos ecológicos distintos, o que, consequentemente, pode exigir diferentes formas de controle e erradicação.

- O maior número de espécies exóticas invasoras foi observado no Passeio Público, seguido pelo Parque São Lourenço, Parque Bacacheri, Parque Municipal Barigui e Parque Municipal Passaúna.

- As espécies exóticas invasoras que apresentaram o maior número de indivíduos nos parques foram: Ligustrum lucidum (alfeneiro), no Passeio Público, Parque Bacacheri, Parque São Lourenço, Parque Municipal Barigui e Parque Municipal do Passaúna; Pittosporum undulatum (pau-incenso), no Passeio Público, Parque Bacacheri, Parque São Lourenço e Parque Municipal do Passaúna; e Pinus sp. (pínus), no Passeio Público e Parque São Lourenço.

- Psidium guajava foi a única espécie nativa do Brasil considerada invasora no estado do Paraná, encontrada em 3 parques: Passeio Público, Parque Bacacheri e Parque São Lourenço. Esse aspecto no paisagismo ainda é pouco pesquisado e difundido.

\section{REFERÊNCIAS}

ÁLVARES, L. C.; DIAS, P. L. C. Novos paradigmas para a paisagem contemporânea: planejamento ambiental e forma urbana na cidade amazônica. Novos Cadernos NAEA, v. 11, n. 2, p. 123 - 138, 2008.

BIONDI, D.; ALTHAUS, M. Árvores de rua de Curitiba - Cultivo e manejo. Curitiba: FUPEF, 2005. 177 p.

BIONDI, D.; LEAL, L. Caracterização das plantas produzidas no Horto Municipal da Barreirinha, Curitiba/PR. Revista da Sociedade Brasileira de Arborização Urbana, v. 3, n. 2, p. 20 - 36, 2008.

BIONDI, D.; PEDROSA-MACEDO, J. H. Plantas invasoras encontradas na área urbana de Curitiba (PR). Floresta, v. 38, n. 1, p. 129 - 144, 2008.

BOBROWSKI, R. Estrutura e dinâmica da arborização de ruas de Curitiba, Paraná, no período 1984-2010. 144 f. Dissertação (Mestrado em Engenharia Florestal) - Setor de Ciências Agrárias, Universidade Federal do Paraná, Curitiba, 2012.

BURT, J. W.; MUIR, A. A.; PIOVIA-SCOTT, J.; VEBLEN, K. E.; CHANG, A. L.; GROSSMANN, J. D., WEISKEL, H. W. Preventing horticultural introductions of invasive plants: potential efficacy of voluntaries initiatives. Biol. Invasions, v. 9, p. 909 - 923, 2007.

CURITIBA, Prefeitura Municipal de Curitiba. Decreto no 473/2008, de 10 de junho de 2008. Define as espécies florestais consideradas como exóticas invasoras para o município de Curitiba e dá outras providências. Curitiba, 5 jun. 2008.

DECÂNDIDO, R. Recent changes in plant species diversity in urban Pelham Bay Park, 1947-1998. Biological Conservation, n. 120, p. 129 - 136, 2004.

GUIA, G. H.; ALBRETCH, J. M. F.; SOARES, T. S.; TITON, M. Avaliação qualitativa das espécies arbóreas do Parque Antônio Pires de Campos em Cuiabá, MT. Revista da Sociedade Brasileira de Arborização Urbana, Piracicaba, v. 3, n. 3, p. 36 - 43, 2008. 
INSTITUTO DE PESQUISA E PLANEJAMENTO URBANO DE CURITIBA (IPPUC). Desenvolvimento sustentável: indicadores de sustentabilidade de Curitiba - 2010. Curitiba: IPPUC, 2011a. 77 p.

INSTITUTO DE PESQUISA E PLANEJAMENTO URBANO DE CURITIBA (IPPUC). Curitiba em Dados. Disponível em: <http://www.ippuc.org.br/Bancodedados/Curitibaemdados/Curitiba_em _dados_Pesquisa.asp?ampliar=não>. Acesso em: 15/01/2011b.

LIMA NETO, E. M.; MELO, E.; SOUZA, R. Comportamento e características das espécies arbóreas nas áreas verdes públicas de Aracaju, Sergipe. Scientia Plena, v. 7, n. 1, p. 1 - 10, 2011.

MACEDO, S. S. Quadro do paisagismo no Brasil. São Paulo, 1999. 144 p. Coleção Quapá (v. 1).

MACEDO, S. S.; SAKATA, G. S. Parques urbanos no Brasil. 3. ed. São Paulo: Editora da Universidade de São Paulo, 2010. 215 p.

MACK, R. N.; SIMBERLOFF, D.; LONSDALE, W. M.; EVANS, H.; CLOUT, M.; BAZZAA, F. A. Biotic invasions: causes, epidemiology, global consequences and control. Ecol. Appl., n. 10, p. 689 - 710 , 2000.

MIELKE, E. C. Árvores exóticas invasoras em Unidades de Conservação de Curitiba, Paraná: subsídios ao manejo e controle. 103 f. Dissertação (Mestrado em Agronomia) - Setor de Ciências Agrárias, Universidade Federal do Paraná, Curitiba, 2012.

MILANO, M. S. Avaliação e análise da arborização de ruas de Curitiba-PR. 130 f. Dissertação (Mestrado em Engenharia Florestal) - Setor de Ciências Agrárias, Universidade Federal do Paraná, Curitiba, 1984.

MISSOURI BOTANICAL GARDEN. Tropicos. Disponível em: http://www.tropicos.org/. Acesso em: 03/11/2012.

MUSEU BOTÂNICO DO RIO DE JANEIRO. Lista de espécies da flora do Brasil. Rio de Janeiro: 2010. Disponível em: <http://floradobrasil.jbrj.gov.br/2010/>. Acesso em: 03/01/2011.

NOGUEIRA, D. Passeio público, o mais central. Disponível em: <http://www.gazetadopovo.com.br/ imobiliario/conteudo.phtml?tl=1\&id=1002792\&tit=Passeio-Publico-omais-central>. $\quad$ Acesso em: 10/12/2010.

PARANÁ. Instituto Ambiental do Paraná. Portaria IAP nº 074, de 22 de maio de 2007. Reconhece a Lista Oficial de Espécies Exóticas Invasoras para o estado do Paraná, estabelece normas de controle e dá outras providências. Curitiba, 22 maio 2007.

PARQUES. Parques de Curitiba. Disponível em: <http://www.curitiba-parana.net/parques.htm>. Acesso em: 4/07/2012.

PLANO DE AÇÃO PARA OS JARDINS BOTÂNICOS BRASILEIROS. Rio de Janeiro: RBJB, JBRJ, BGCI, 2004. 44 p.

ROTTA, E.; SILVA, I. C.; VICENTINI, L. S. Vegetação arbórea do Passeio Público. Colombo-PR: EMBRAPA-Florestas. Comunicado Técnico nº 129, 2004.

SAKATA, F. G. Paisagismo urbano: requalificação e criação de imagens. São Paulo: Editora da Universidade de São Paulo, 2011. 272 p.

SILVA, L. M.; HASSE, I.; MOCCELIN, R.; ZBORALSKI, A. R. Arborização de vias públicas e a utilização de espécies exóticas: o caso do bairro Centro de Pato Branco/PR. Scientia Agraria, v. 8, n. 1, p. 47 - 53, 2007a.

SILVA, L. M.; MOCCELLIN, R.; WEISSHEIMER, D. I.; ZBORALSKI, A. R.; FONSECA, L.; RODIGUIERO, D. A. Inventário e sugestões para arborização de via pública de Pato Branco/PR. Revista da Sociedade Brasileira de Arborização Urbana, Piracicaba, v. 02, n. 01, p. 101 - 108, 2007 b. 
SECRETARIA MUNICIPAL DE MEIO AMBIENTE DE CURITIBA (SMMAC). Parques e Bosques. Disponível em: 〈http://www.curitiba.pr.gov.br/secretaria.aspx?o=5>. Acesso em: 25/02/2006.

ZILLER, S. R.; ZALBA, S. Propostas de ação para prevenção e controle de espécies exóticas invasoras. Natureza \& Conservação, Curitiba, v. 5, n. 2, p. 8 - 15, 2007.

ZILLER, S. R.; ZENNI, R. D.; GRAF NETO, J. Invasões biológicas: introdução, impactos e espécies invasoras no Brasil. In: PEDROSA-MACEDO, J. H.; BREDOW, E. A. (eds.) Princípios e rudimentos do controle biológico de plantas: coletânea. Curitiba: UFPR, 2004. p. 17 - 41. 